\title{
LncRNA Expression Profile of Human Thoracic Aortic Dissection by High- Throughput Sequencing
}

\author{
Jie Sun ${ }^{\mathrm{a}, \mathrm{b}}$ Guojun Chen ${ }^{\mathrm{a}} \quad$ Yuanwen Jing $^{\mathrm{a}} \quad{\text { Xiang He } \mathrm{He}^{\mathrm{a}} \text { Jianting Dong }}^{\mathrm{b}}$ \\ Junmeng Zheng ${ }^{b}$ Meisheng Zou ${ }^{a, c} \quad$ Hairui Li $^{a}$ Shifei Wang ${ }^{a}$ Yili Sun ${ }^{a}$ \\ Wangjun Liao ${ }^{d}$ Yulin Liao ${ }^{a}$ Li Feng ${ }^{a, b}$ Jianping Bin ${ }^{a}$
}

aState Key Laboratory of Organ Failure Research, Department of Cardiology, Nanfang Hospital, Southern Medical University, Guangzhou, 'Department of Cardiology, Zhongshan Hospital, Sun Yat-sen University, Zhongshan, 'Wards of Cadres, Guangzhou General Hospital of Guangzhou Military Region, Guangzhou, dDepartment of Oncology, Nanfang Hospital, Southern Medical University, Guangzhou, China

\section{Key Words}

Human thoracic aortic dissection (TAD) • Long non-coding RNA (IncRNA) • High throughput sequencing (HTS) • Bioinformatics analyses

\begin{abstract}
Background/Aims: In this study, the long non-coding RNA (IncRNA) expression profile in human thoracic aortic dissection (TAD), a highly lethal cardiovascular disease, was investigated. Methods: Human TAD $(n=3)$ and normal aortic tissues (NA) $(n=3)$ were examined by highthroughput sequencing. Bioinformatics analyses were performed to predict the roles of aberrantly expressed IncRNAs. Quantitative real-time polymerase chain reaction (qRT-PCR) was applied to validate the results. Results: A total of 269 IncRNAs (159 up-regulated and 110 down-regulated) and 2, 255 mRNAs (1 294 up-regulated and 961 down-regulated) were aberrantly expressed in human TAD (fold-change $>1.5, P<0.05$ ). QRT-PCR results of five dysregulated genes were consistent with HTS data. A IncRNA-mRNA coexpression analysis showed positive correlations between the up-regulated IncRNA (ENSG00000269936) and its adjacent up-regulated mRNA (MAP2K6, $R=0.940, P<0.01$ ), and between the down-regulated IncRNA_1421 and its down-regulated mRNAs (FBLN5, $R=0.950, P<0.01 ; A C T A 2, R=0.96$, $P<0.01 ;$ TIMP3, $R=0.96, P<0.05)$. The IncRNA-miRNA-mRNA network indicated that the upregulated IncRNA XIST and $p 21$ had similar sequences targeted by has-miR-17-5p. The results of luciferase assay and fluorescence immuno-cytochemistry were consistent with that. And qRT-PCR results showed that IncRNA XIST and $p 21$ were expressed at a higher level and hasmiR-17-5p was expressed at a lower level in TAD than in NA. The predicted binding motifs of three up-regulated IncRNAs (ENSG00000248508, ENSG00000226530, and EG00000259719) were correlated with up-regulated $R U N X 1$ ( $R=0.982, P<0.001 ; R=0.967, P<0.01 ; R=0.960$, $P<0.01$, respectively). Conclusions: Our study revealed a set of dysregulated IncRNAs and predicted their multiple potential functions in human TAD. These findings suggest that IncRNAs are novel potential therapeutic targets for human TAD.

Professor Jianping Bin and Li Feng

State Key Laboratory of Organ Failure Research, Department of Cardiology, Nanfang Hospital, Southern Medical University, 1838 North Guangzhou Avenue, Guangzhou 510515 (China) Tel. +86 20 61642365; E-Mail jianpingbin@hotmail.com, fengli89880246@126.com
\end{abstract}

\section{KARGER}




\section{Cellular Physiology Cell Physiol Biochem 2018;46:1027-1041 \\ \begin{tabular}{l|l} 
and Biochemistry Published onlıne: April18, 2018 & $\begin{array}{l}\text { (c) } 2018 \text { The Author(s). Published by S. Karger AG, Basel } \\
\text { www.karger.com/cpb }\end{array}$
\end{tabular}}

Sun et al.: LncRNA Expression in Thoracic Aortic Dissection

\section{Introduction}

Acute thoracic aortic dissection (TAD) is one of the most lethal cardiovascular diseases, even when treated with conventional pharmacological approaches, classic surgical procedures, or endovascular intervention. In addition to remedial treatments, the clinical control of traditional risk factors, including hypertension, dyslipidemia, and congenital cardiovascular abnormalities, reduces the incidence of TAD. However, even with effective management or in the absence of risk factors, TAD may still occur. Consequently, effective therapeutic targets are needed to prevent the pathological progression of TAD, including a loss of smooth muscle cells (SMC) and dynamic imbalance of the extracellular matrix (ECM). Despite great progress, the mechanisms underlying TAD are still not fully understood, thereby limiting the identification of potential targets $[1,2]$.

Non-coding RNAs are rapidly emerging as crucial regulatory molecules in the development of aortic diseases. MicroRNAs (miRs or miRNAs) are associated with both aortic SMC apoptosis and ECM degradation [3-9]._ENREF_6_ENREF_2 In addition, long noncoding RNAs (lncRNAs) are involved in various biological processes via the dysregulation of target gene expression [10,11]. They also play important roles in pathophysiological changes of vascular SMC and ECM. Various IncRNAs, such as ANRIL, SENCR, LnCRNA HIF1$A S 1$, and lincRNA-p21, are involved in the regulation of human vascular SMC proliferation, contraction, migration, and apoptosis [12-15]. The lncRNA HAS2-AS1 is involved in ECM remodeling via the regulation of HAS2 transcription in vascular SMC [16]. Generally, lncRNA research related to human TAD has focused on their functions in individual cells. To date, no study has investigated the IncRNA expression profile in TAD tissues, particularly in human TAD tissues.

In addition, previous studies have mainly used microarray technology, to which cannot be used for whole-transcriptome analyses. Owing to its ability in whole transcriptome analyses, high-throughput sequencing (HTS) technology is more suitable to characterize the genetic basis of diseases compared with microarrays. Therefore, we used HTS to investigate the IncRNA expression profile in human TAD tissues, and further applied a series of bioinformatics analyses to predict the functions of these lncRNAs.

\section{Materials and Methods}

\section{Patient sample preparation and ethics statement}

The study protocol was approved by the Research Ethics Committees of both Zhongshan Hospital, Sun Yat-sen University and Guangzhou General Hospital of Guangzhou Military Region. Normal aortic (NA) tissues of donors $(n=3)$ and TAD tissues of patients $(n=3)$ were obtained from Zhongshan Hospital, Sun Yat-sen University and Guangzhou General Hospital of Guangzhou Military Region after informed consent was obtained (Table 1). The diagnosis of TAD was confirmed by the computed tomography angiography. All resected ascending aorta tissues following surgery were immediately frozen in liquid nitrogen and stored at $-80^{\circ} \mathrm{C}$ until RNA extraction was performed.

Hematoxylin and eosin staining and immunohistochemistry staining

Samples were fixed by paraformaldehyde and then embedded in paraffin. Then, paraffin-embedded samples were cut into $4 \mu \mathrm{m}$-thick sections and stained with Hematoxylin and eosin stain (H\&E) and immunohistochemistry with an antibody against SMC $\alpha$-actin (Sigma, USA), to confirm the formation of aortic dissection. Slides were visualized using an optical microscope (OLYMPUS BX51, Olympus Optical, Tokyo, Japan) under different magnification.

Table 1. Clinical characteristics of TAD and NA groups. TAD, thoracic aortic dissection; NA, normal donors without aortic diseases

\begin{tabular}{lcc}
\hline & TAD $(\mathrm{n}=3)$ & NA $(\mathrm{n}=3)$ \\
\hline Age(years) & $43.4 \pm 6.2$ & $38.6 \pm 5.3$ \\
Males/females & $3 / 0$ & $3 / 0$ \\
Smoking & 2 & 1 \\
Atherosclerosis & 0 & 0 \\
Hypertension & 2 & 1 \\
\hline
\end{tabular}




\section{Cellular Physiology Cell Physiol Biochem 2018;46:1027-1041 \begin{tabular}{l|l} 
and Biochemistry & DOI: 10.1159/000488834 \\
Publisned 2018 The Author(s). Published by S. Karger AG, Basel \\
www.karger.com/cpb
\end{tabular} \\ \begin{tabular}{lll} 
Published online: April 18, $2018 \quad$ www.karger.com/cpb \\
\hline Sun et al.
\end{tabular}}

\section{Total RNA extraction}

Total RNA was extracted from the tissue samples (50-100 mg tissue) using the TRIzol reagent (Invitrogen, Carlsbad, CA) according to the manufacturer's protocol. Then RNA degradation and contamination was detected by $1 \%$ agarose gels. RNA integrity and concentration was assessed by the RNA Nano 6000 Assay Kit of the Bioanalyzer 2100 system (Agilent Technologies, CA, USA). The samples were preserved at $-80^{\circ} \mathrm{C}$ for further analysis.

Library construction, examination, clustering, sequencing, quality control and gene expression analysis

Ribosomal RNA was removed from $3 \mu \mathrm{g}$ of total RNA (including mRNAs and IncRNAs) by Human Epicentre Ribo-Zero ${ }^{\mathrm{TM}}$ Gold Kits (Epicentre, US). Then, the sequencing libraries were generated according to the manufacturer's instructions with varied index label by NEBNext ${ }^{\circledR}$ Ultra ${ }^{\mathrm{TM}}$ Directional RNA Library Prep Kit for Illumina (NEB, Ispawich, USA). After that, the qualification and quantification of library insert size were assessed respectively using the Agilent Bioanalyzer 2100 system (Agilent Technologies, CA, USA) and Taqman fluorescence probe of AB Step One Plus Real-Time PCR system (Library valid concentration $>10 \mathrm{nM}$ ). Subsequently, the cluster was generated following the performance of clustering of the index-coded specimen on a cBot cluster generation system through TruSeq PE Cluster Kit v4-cBot-HS (Illumina). At last, all libraries were sequenced through an Illumina Hiseq 4000 platform, and 150 bp paired-end reads were generated.

Sequencing-received raw data was filtered by Perl scripts to ensure the quality of data. And the clean data was obtained by removing all adaptor-polluted reads, low quality tags, empty reads, and reads whose number of $\mathrm{N}$ bases accounting for more than $5 \%$ from raw sequences. Then, the obtained clean data was carried out on statistics analyses on its quantity and quality.

DEGseq v1.18.0 was used for differential gene expression analysis between two samples.

Gene expression level and conservation Analysis

HTSeq v0.6.0 was used to count the Reads Count for each gene in each sample. RPKM (Reads Per Kilobase Millon Mapped Reads) was calculated to estimate gene expression levels in each sample.

Then both the IncRNA GTF file merged by Cuffmerge v2.2.1 and PhastCons data from UCSC database were abtained. With these two data sets, the exon number, length, JS score and conservation analysis could be performed for each transcript.

Gene ontology enrichment and pathway analyses

A Gene Ontology (GO) analysis was used to examine the functions of aberrantly expressed mRNAs according to the Database for Annotation, Visualization and Integrated Discovery (DAVID; http://david. abcc.ncifcrf.gov/). A pathway analysis was used to identify the roles of aberrantly expressed protein-coding genes in biological pathways based on the Kyoto Encyclopedia of Genes and Genomes pathways (KEGG), Biocarta, and Reactome (http://www.genome.jp/kegg/). Fisher's exact tests were used for the classification of the GO terms and selection of significant pathways. The threshold for significance was $P<0.05$.

\section{LncRNA and mRNA coexpression analysis}

To determine the functions of IncRNAs in the regulation of target gene expression in cis and in trans, the relationship between the predicted potential target genes of aberrantly expressed lncRNAs and the aberrantly expressed mRNAs was examined. The threshold for significance was defined as $0 R \geq 0.8$ and $P<0.05$. The predicted potential target genes whose loci were within a $10-\mathrm{kb}$ window upstream or downstream of the given aberrantly expressed lncRNA were considered cis-regulated genes. Other genes were identified as a trans-regulated. To create a visual representation, an lncRNA-mRNA regulatory network was constructed using Cytoscape 3.0.

LncRNA-miRNA-mRNA network

To determine the function of aberrantly expressed lncRNAs as ceRNAs in TAD, an aberrantly expressed IncRNA-miRNA regulatory network was established using starBasev2.0 [17]._ENREF_12 Then, the target mRNAs of miRNAs affected by the potential ceRNAs were predicted using miRTarBase.

siRNA transfection

The short interfering RNA (siRNA) was used for inhibiting endogenous RNA expression. Four siRNAs, include Si1, Si2, Si3 and Si4 were designed for the knockdown of XIST which could originally up-regulate 


\section{Cellular Physiology Cell Physiol Biochem 2018;46:1027-1041 \begin{tabular}{l|l} 
and Biochemistry Published online: April 18, 2018 & $\begin{array}{l}\text { (c) } 2018 \text { The Author(s). Published by S. Karger AG, Basel } \\
\text { www.karger.com/cpb }\end{array}$ \\
\hline
\end{tabular} \\ Sun et al.: LncRNA Expression in Thoracic Aortic Dissection}

the expression of p21. Si1 which was the most powerfully down-regulating the expression of p21, was named as human XIST RNA interference (siRNA) and chosen for subsequent experiments. The human XIST RNA interference (siRNA) target sequence was 5'- ACCTCTCCTTTCTCTGCCTAC-3', and a scramble form was performed as a control, 5'-UUCUCCGAACGUGUCACGUT-3'. The human p21 RNA interference (siRNA) target sequence was $5^{\prime}$-AAGAAAAGCAGACCUACUCCA-3', and a scramble form was performed as a control, 5'-UUCUCCGAACGUGUCACGUT-3'. The antagomiR-17-5p sequence (anti-miR-17-5p) was 5'-GTACCTGCACTGTAAGCACTTTG-3', and the miR-17-5p-negative control (miR-17-5p-NC) sequence was $5^{\prime}$-CAGAUACGUUACAGUGCAGGUAG-3'. Then, the adenoviruses harbouring those sequences were respectively constructed using the Lipofectamine 2000 (Invitrogen) according to the mnufacturer's instruction.

\section{Luciferase Assay}

The loss of SMCs is one of the main pathological progressions of TAD. And the SMCs are the intrinsic cells in the aorta wall. In that, we chose it for present study. Human aortic SMCs (Cellbio Bionengineering Co., Ltd, Shanghai, China) were cultured in 96-well plates $(5 \times 103$ cells/well) $24 \mathrm{~h}$ and cotransfected with the wild-type (WT) or mutated (Mut) XIST reporter vector, and has-miR-17-5p or its mimics. After lysates harvested $24 \mathrm{~h}$, renilla luciferase activities were measured according to the dual-luciferase assay manual (Promega).

\section{Fluorescence Immuno-cytochemistry}

Human aortic SMCs were transfected with si-XIST or si-XIST and anti-miR-17-5p (si-XIST + anti-mir175p) or si-XIST, anti-miR-17-5p and si-p21 (si-XIST + anti-mir17-5p + si-p21) or left untreated for 48h. Then fixed SMCs were incubated respectively with the two primary antibodies, including anti-ki67 (CST, dilution 1:200) and anti-H3P (abcam, dilution 1:100). And Alexa Fluor 488 or Alexa Fluor 594 as the secondary antibodies (BIOSS antibodies, dilution of 1:200) was applied for fluorescent confocal analysis.

\section{Transcription factor (TF) target prediction}

TF regulates gene transcription via binding to sequence motifs of genomic DNA is one of the important regulatory mechanisms of gene expression. Therefore, sequence motifs of DNA from $2.0 \mathrm{~kb}$ upstream of the transcription start site of aberrantly expressed lncRNAs were predicted. Accordingly, sequence motifs of aberrantly expressed IncRNAs whose expression levels were most strongly positively correlated (OR $>0.90)$ with the expression levels of aberrantly expressed TFs were mapped to the genome in the Jaspar database (http://jaspar.genereg.net/). Then, those TFs whose prediction score were greater than 8 were selected. A Pearson's correlation analysis was used to measure the regulatory ability of transcription factors by calculating the correlation between TFs and lncRNAs.

\section{Quantitative real-time polymerase chain reaction}

QRT-PCR was performed to validate high-throughput sequencing results using SYBR Green assays. Total RNA was reverse-transcribed using the Reverse Transcription Kit (Takara, Tokyo, Japan). The U6 was used as internal controls for miRNA, and GAPDH was used for IncRNA and mRNA. Fold changes in expression were calculated using $2^{-\Delta \Delta \mathrm{Ct}}$ method. All primers used in this study are listed in Table 2.

\section{Statistical analysis}

All statistical analyses, including comparisons using the Student's $t$-test, unpaired $t$-test, Fisher's exact test, $\mathrm{x}^{2}$ test, and Pearson's correlation, as appropriate, were performed using SPSS 19.0 (SPSS, Chicago, IL, USA). $P$-values of $<0.05$ were considered statistically significant, and all the statistical analyses were two-sided.
Table 2. Primers used in analysis of genes expression by qRT-PCR

\begin{tabular}{lcc}
\hline Primer name & Primer FW(5'-3') & Primer RW(5'-3') \\
\hline NEAT1 & GACCCTCACCTACCCACCT & ATGCCCAACTAGACCTGCC \\
XIST & CTGCTGATCATTTGGTGGTGT & CTCTGCCTGACCTGCTATCAT \\
IncRNA_1421 & AGGGAGTTTCTGCAACCAGATT & AGCACTGCTTTGTGGGAGC \\
ENSG00000248508 & CTAACTCTGCCACACACGGT & GCTCAGACCTGCAACCTCTT \\
ENSG00000226530 & GGGTGAAGAGTTGCCACACA & CCCAAGAGTTTCACAGAAGCG \\
ENSG00000259719 & ATTGCCCTGGTCACCTCAAC & GGATGCCGAGAACTCACACC \\
has-miR-17-5p & ACTACCTGCACTGTAAGCACTTTG & \\
U6 & CAAATTCGTGAAGCGTTCCATAT & \\
ACTB & CATGTACGTTGCTATCCAGGC & CTCCTTAATGTCACGCACGAT \\
MYH11 & GCAGCTTGGAAATATCGTCT & TGGATCTGGTGAAATCTGTC \\
FBLN5 & AGCAACCAATGTGTGGATGTG & TGGCAGTAACCATAGCGACAT \\
ACTA2 & TGTGAAGCAGCTCCAGCTATG & TTGCTCTGTGCTTCGTCACC \\
TIMP3 & TCTGCAACTCCGACATCG & TTGGTGAAGCCTCGGTACAT \\
RUNX1 & CACCTACCACAGAGCCATCA & CTCGGAAAAGGACAAGCTCC \\
GAPDH & AGGTGAAGGTCGGAGTCAAC & CGCTCCTGGAAGATGGTGAT \\
\hline
\end{tabular}




\section{Cellular Physiology Cell Physiol Biochem 2018;46:1027-1041

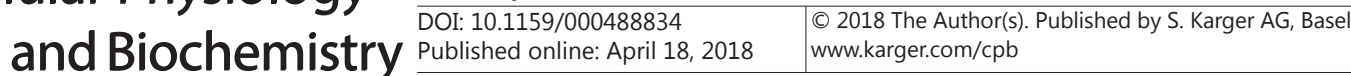

\section{Results}

$H \& E$ and immunohistochemistry staining of aortic tissues

Normal aortic tissue showed a complete and continuous aortic structure, including intima, tunica media and adventitia (Fig. 1A). Specimens of aortic dissection showed a separation between intima and tunica media with thrombus formation in the dissected location (Fig. 1B). Marked changes of SMC in normal and dissected aortic location were also observed in immunohistochemical staining with an antibody against SMC $\alpha$-actin (Fig. 1C-D).

\section{Characteristics of IncRNAs and mRNAs}

To examine aberrant expression, we performed HTS of lncRNAs and mRNAs in both TAD and NA tissues. The IncRNA and mRNA expression profiles were highly correlated among the 6 samples (Fig. 2A). Moreover, compared with mRNAs, IncRNAs showed lower transcript abundances (Fig. 2B), higher tissue specificity (Fig. 2C), and less conservation (Fig. 2D). The lncRNAs had more than 2 exons and were longer than 200bp (Fig. 2E and F). These properties are consistent with the typical expression features of lncRNAs [18].

\section{Profiles of the aberrantly expressed IncRNAs and mRNAs}

The correlations between aberrantly expressed lncRNA and mRNAexpression profiles were much higher within groups than that among samples (Fig. 3A), indicating that the results were highly reliable. A total of

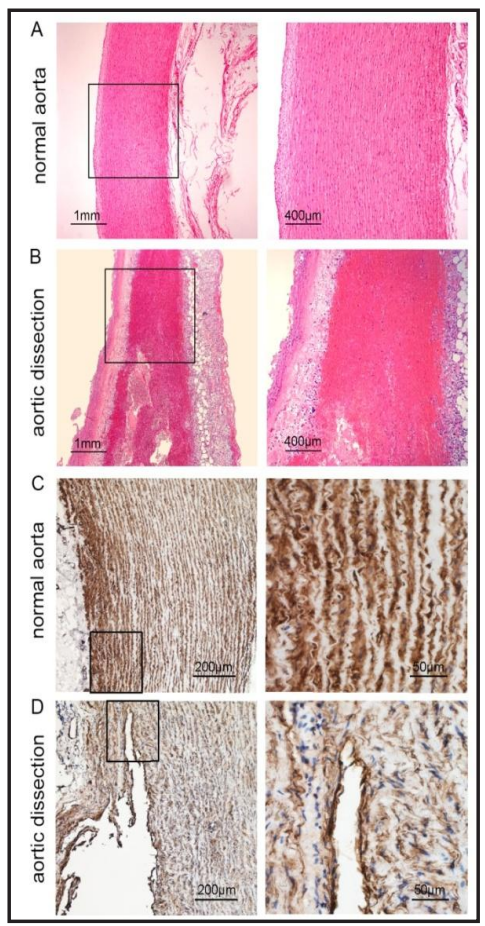

Fig. 1. H\&E and immunohistochemical staining of aortic tissues. H\&E staining of normal aortic tissue (A) and aortic dissection tissue (B). Immunohistochemical staining of SMC in normal aorta (C) and aortic dissection tissue (D) with an antibody against SMC $\alpha$-actin.
Fig. 2. Comparisons of IncRNA and mRNA characteristics in TAD and normal arotic tissues. (A) The correlations among IncRNA and mRNA expression profiles in six samples. (B) RPKM (reads per kilobase per million) distribution for IncRNAs and mRNAs. (C) JS Score Distribution (Jensen Shannon Score Distribution) for lncRNAs and mRNAs. (D) Conservation score fortwo individual subtypes of lncRNAs (lncRNA-exon and lncRNA-gene) and mRNAs. (E) Distribution of the number of exons in lncRNAs and mRNAs. (F) Distribution of transcript lengths in lncRNAs and mRNAs. NA represents normal arotic tissue; TAD represents thoracic aortic dissection tissue.

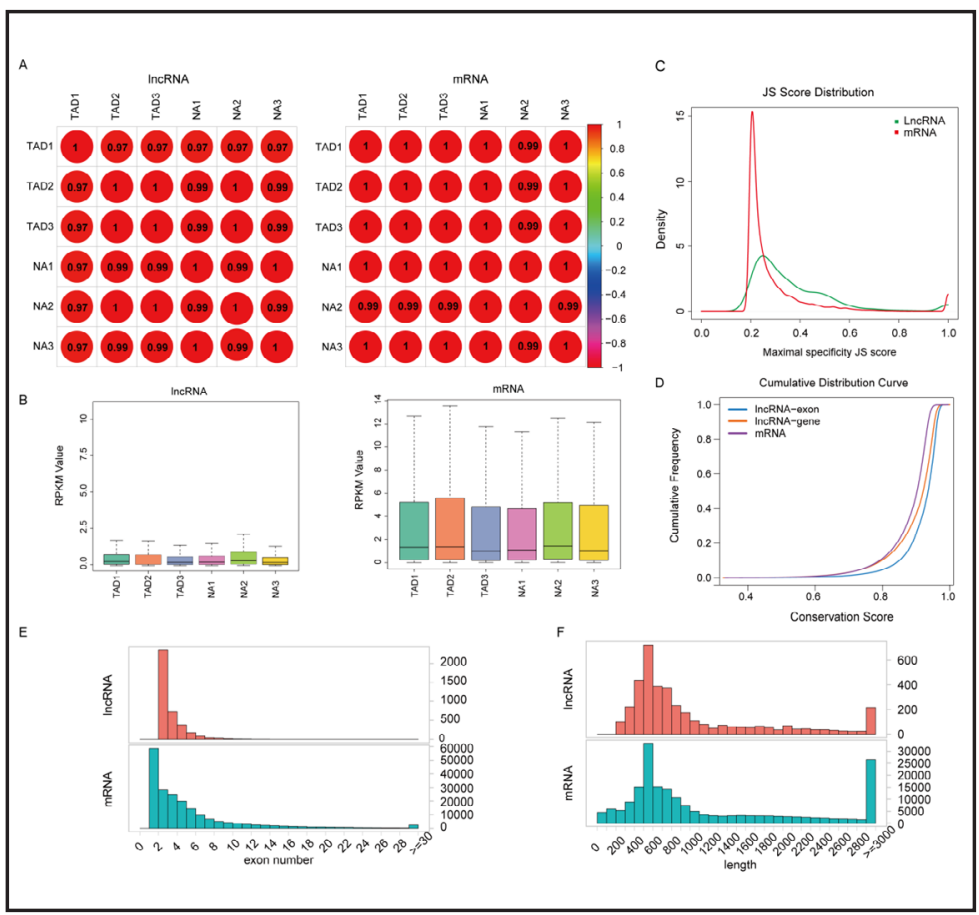




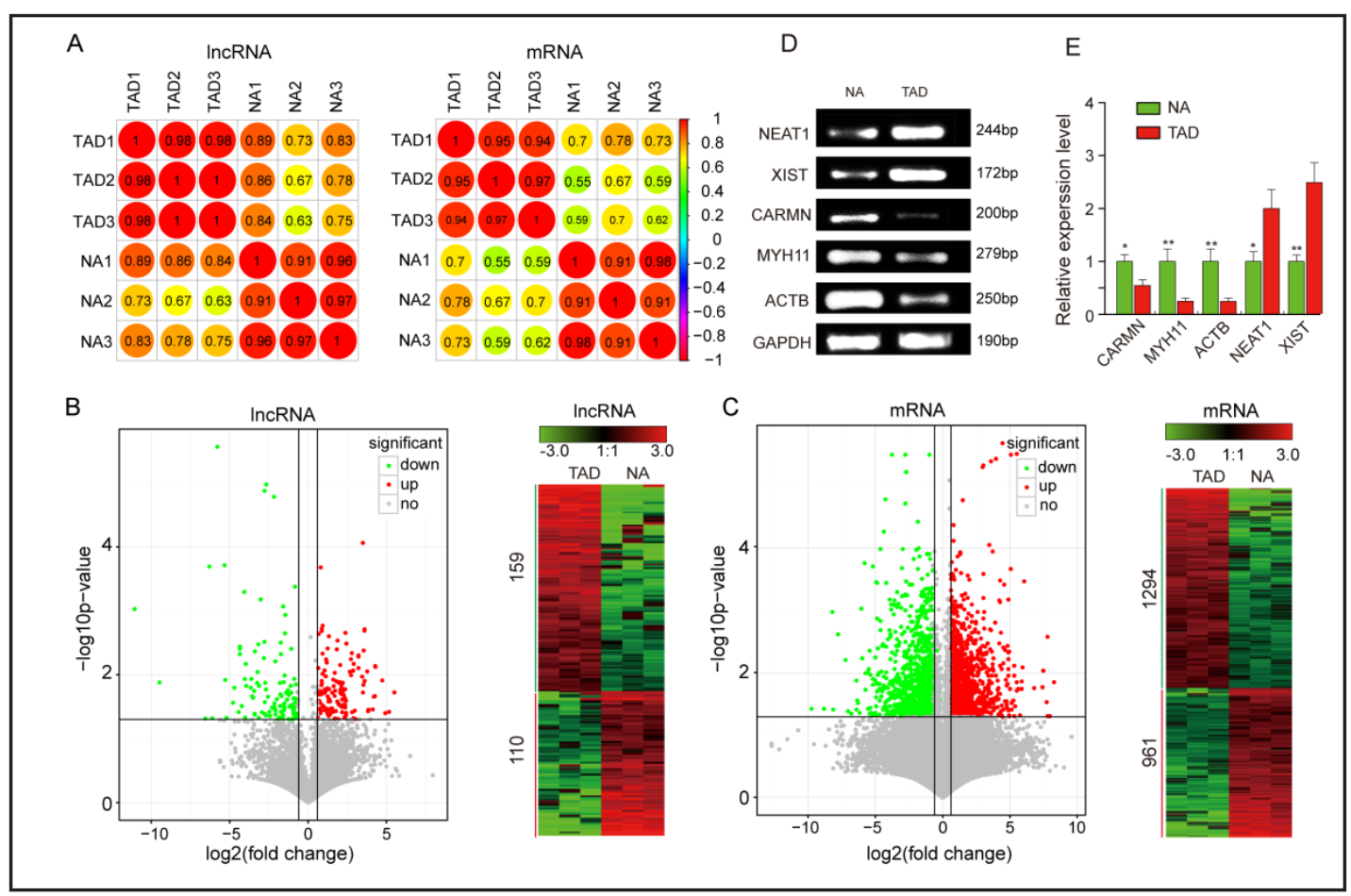

Fig. 3. Aberrantly expressed genes in TAD and normal arotictissue samples. (A) The correlationsbetweenaberrantly expressed lncRNA and mRNA expression profilesfor 6 samples. (B) Volcano plot and hierarchically clustered heatmap illustratingdifferentiallyexpressed lncRNAs between TAD and normal arotic tissue samples. Up-regulated lncRNAs are denoted in red and down-regulated in green. (C) Volcano plot and hierarchically clustered heatmap illustratingdifferentially expressedmRNAs between TAD and normal arotic tissue samples. ( $\mathrm{P} \leq 0.05$ and fold change $\geq 2.0$ ). Up-regulated mRNAs are denoted in red and down-regulated in green. (D) and (E) QRT-PCR validation for five aberrantly expressed lncRNAs. (D) qRT-PCR was used to compare the relative expression levels of three aberrantly expressed IncRNAs (NEAT1, XIST and CARMN) and two aberrantly expressed mRNAs (MYH11and ACTB). GAPDH was amplified as an internal control. (E) Histogramof the expression levels of five aberrantly expressed genes in TAD and NA.NA represents normal arotic tissue; TAD represents thoracic aortic dissection tissue. ${ }^{*} \mathrm{P}<0.05$ vs. NA. ${ }^{* *} \mathrm{P}<0.01$ vs. NA.

269 IncRNAs (159 up-regulated and 110 down-regulated) and 2, 255 mRNAs (1, 294 upregulated and 961 down-regulated) were significantly aberrantly expressed in TAD tissues compared with those in NA tissues (fold-change $>1.5, \mathrm{P}<0.05$ ). The top 10 dis-regulated (up-regulated and down-regulated) unknown lncRNAs, known lncRNAs and mRNAs were respectively shown in Table 3, 4 and 5. A hierarchically clustered heat map and volcano plots illustrate differentially expressed lncRNA (Fig. 3B) and mRNA (Fig. 3C) between TAD and NA tissues.

Three aberrantly expressed lncRNAs (NEAT1, XIST and CARMN) and two aberrantly expressed mRNAs (MYH11and ACTB) were selected for qRT-PCR analyses (Fig. 3D and E). Based on the qRT-PCR results, three genes (CARMN, MYH11, and ACTB) exhibited lower expression and two genes (NEAT1 and XIST) exhibited higher expression in TAD than in NA tissues. The qRT-PCR results were generally consistent with those of HTS. Additionally, several established biomarkers of aortic disorders were detected, including two up-regulated genes and eight down-regulated genes (Table 6) [19]. To some extent, these findings provided additional validation of our results.

GO and KEGG enrichment analyses ofaberrantly expressed mRNAs

Both GO and KEGG enrichment analyses were used to determine the functions of aberrantly expressed mRNAs. A GO enrichment analysis showed that the up-regulated 
Table 3. Top 10 up-regulated and down-regulated unknown lncRNAs (TAD vs.NA)

\begin{tabular}{|c|c|c|c|c|c|c|c|}
\hline Gene & $\begin{array}{l}\text { chromosomal } \\
\text { position }\end{array}$ & TAD normalize & NA normalize & $\log \mathrm{FC}$ & P-value & $\begin{array}{l}\text { Up/ } \\
\text { Down }\end{array}$ & $\begin{array}{l}\begin{array}{c}\text { nearest } \\
\text { mRNA }\end{array} \\
\text { mate }\end{array}$ \\
\hline Inc_1935 & $\begin{array}{l}\text { Chromosome 12: } \\
50,286,244- \\
50,289,231:+\end{array}$ & 433.9894 & 0.01 & 15.40537232 & $1.72 \mathrm{E}-12$ & up & LMA1 \\
\hline Inc_2758 & $\begin{array}{l}\text { Chromomome X: } \\
\text { 119,466,034: } \\
119,468,262:\end{array}$ & 348.8934 & 0.01 & 15.09049885 & $1.07 \mathrm{E}-11$ & up & SLC25A5 \\
\hline Inc_817 & $\begin{array}{l}\text { Chromosome 5: } \\
\text { 149,406,879: } \\
149,428,678: *\end{array}$ & 224.7363 & 0.01 & 14.45594533 & $1.61 \mathrm{E}-09$ & up & IL17 B \\
\hline Inc_2433 & $\begin{array}{l}\text { Chromosome en: } \\
\text { 14,210,488: } \\
\text { 14,217,922:+ }\end{array}$ & 192.3721 & 0.01 & 14.23161223 & $2.18 \mathrm{E}-09$ & up & $\operatorname{cox} 10$ \\
\hline Inc_2276 & $\begin{array}{l}\text { Chromosome 15: } \\
\text { 81,953,303: } \\
\text { 81,955,666:- }\end{array}$ & 156.5486 & 0.01 & 13.93432257 & $2.24 \mathrm{E}-08$ & up & МЕХЗВ \\
\hline Inc_1826 & $\begin{array}{c}\text { Chromonome 11: } \\
71,807,591- \\
71,818,238:- \\
\text { Chromosome } 2 .\end{array}$ & 133.305 & 0.01 & 13.70244308 & $9.10 \mathrm{E}-08$ & up & ZNF705E \\
\hline Inc_316 & $\begin{array}{c}\text { Chromosomit. } \\
19,026,641 . \\
\text { 19,022,487:- } \\
\text { Chromosome 14: }\end{array}$ & 114.4818 & 0.01 & 13.48283096 & $2.63 \mathrm{E}-07$ & up & OSR1 \\
\hline Inc_2100 & 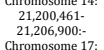 & 108.257 & 0.01 & 13.40217234 & $2.94 \mathrm{E}-07$ & up & HNRNPC \\
\hline Inc_2430 & $\begin{array}{l}\text { Chromosome 17: } \\
13,940,571 \\
13,932,990:- \\
\text { Chromosome }\end{array}$ & 81.9696 & 0.01 & 13.00087332 & $1.57 \mathrm{E}-06$ & up & $\operatorname{cox} 10$ \\
\hline Inc_971 & $\begin{array}{r}\text { Chromosome e: } \\
137,723,63- \\
137,825,894:- \\
\text { Chromosome } 20 .\end{array}$ & 58.68159 & 0.01 & 12.51869224 & $8.24 \mathrm{E}-06$ & up & TNFAIP3 \\
\hline Inc_2665 & $\begin{array}{c}\text { Chromosome e 20: } \\
44,656,451- \\
44,696,096-- \\
\text { Chromosome } 20 \text { : }\end{array}$ & 0.01 & 38.04268 & -11.89340335 & $7.70 \mathrm{E}-05$ & down & ADA \\
\hline Inc_2667 & $\begin{array}{c}\text { Chromosome 20: } \\
45,447,232- \\
45,435,971:- \\
\text { Chromosome } 22:\end{array}$ & 0.01 & 26.89786 & -11.39327584 & 0.000349671 & down & PIGT \\
\hline Inc_2703 & $\begin{array}{l}\text { Chromosome 22: } \\
\text { 11,868, } \\
\text { 11,974,044: } \\
\text { Chromosome }\end{array}$ & 0.01 & 29.07035 & -11.5053329 & 0.000295451 & down & OR11H1 \\
\hline Inc_1145 & $\begin{array}{r}153,411,234: \\
\text { 153,413,963: } \\
\text { Chromosome 17: }\end{array}$ & 0.01 & 296.2307 & -14.85443354 & $1.95 \mathrm{E}-11$ & down & DPP6 \\
\hline Inc_2468 & 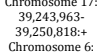 & 0.01 & 51.78437 & -12.33830104 & $1.19 \mathrm{E}-05$ & down & FBXL20 \\
\hline Inc_950 & $\begin{array}{l}\text { 131,868,013- } \\
\text { 113,873,351:- }\end{array}$ & 0.01 & 18.61126 & -10.86196032 & 0.001385051 & down & MARCKS \\
\hline Inc_1019 & $\begin{array}{l}\text { Chromosome 6: } \\
2,621,913- \\
2,634,603:-\end{array}$ & 0.01 & 182.0942 & -14.1523976 & $9.72 \mathrm{E}-10$ & down & MYLK4 \\
\hline Inc_1162 & $\begin{array}{l}\text { Chromosome 7: } \\
\text { 25,593,351- } \\
\text { 25,663,053:- } \\
\text { Chromosome 5: }\end{array}$ & 0.01 & 30.96043 & -11.59620998 & 0.000125116 & down & NPVF \\
\hline Inc_839 & $\begin{array}{l}\text { Chromosome e: } \\
\text { 173,707,614: } \\
173,746,209:-\end{array}$ & 0.01 & 47.27378 & -12.20682446 & $1.23 \mathrm{E}-05$ & down & CPEB4 \\
\hline Inc_1415 & $\begin{array}{l}\text { Chromosomem: } \\
\text { 103,140,53: } \\
\text { 103,325,034:- }\end{array}$ & 0.01 & 1335.465 & -17.02698268 & 4.46E-16 & down & CYLC2 \\
\hline
\end{tabular}

Table 5. Top 10 up-regulated and down-regulated mRNAs (TAD vs.NA)

\begin{tabular}{|c|c|c|c|c|c|c|}
\hline $\begin{array}{l}\text { Gene } \\
\text { FNSC000016735 }\end{array}$ & $\begin{array}{l}\text { Gene symbol } \\
\end{array}$ & $\begin{array}{l}\text { TAD normalize } \\
233602334\end{array}$ & $\begin{array}{l}\text { NA normalize } \\
0 \text { 04672 }\end{array}$ & 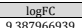 & 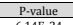 & Up/Down \\
\hline $\begin{array}{l}\text { ENSGG000001063735 } \\
\text { ENSG00000120337 }\end{array}$ & $\begin{array}{c}\text { CCLL5 } \\
\text { TNFSF18 }\end{array}$ & $\begin{array}{l}233.6023344 \\
37.686702\end{array}$ & $\begin{array}{l}0.348672 \\
0.348672\end{array}$ & $\begin{array}{l}9.3879669939 \\
6.756039697\end{array}$ & $\begin{array}{l}\begin{array}{l}6.1442-24 \\
2.95 E-07\end{array} \\
\text { 2. }\end{array}$ & \\
\hline ENSGO00000125744 & FOSB & 8843.173421 & 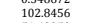 & 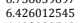 & 1.99E-11 & \\
\hline ENSG000000164326 & CARTPT & 4383.868420 & 51.62358 & 6.408030513 & $\begin{array}{l}2.44 E-06 \\
2.88-05\end{array}$ & up \\
\hline 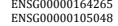 & $\begin{array}{l}\text { SCGBBAA2 } \\
\text { TNNT1 }\end{array}$ & $\begin{array}{l}22.6001086 \\
15.909210\end{array}$ & $\begin{array}{l}0.320167 \\
0.325334\end{array}$ & $\begin{array}{l}\begin{array}{l}6.1414421082 \\
5.611796358\end{array} \\
\end{array}$ & $\begin{array}{c}2.88 \mathrm{E}-05 \\
0.000629251\end{array}$ & \\
\hline ENSG00000109321 & AREG & 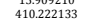 & $\begin{array}{l}0.3525354 \\
8.692247007\end{array}$ & $\begin{array}{l}5.6117605386 \\
5.56052352\end{array}$ & $\begin{array}{l}0.000023 \mathrm{E}-22 \\
62.22\end{array}$ & up \\
\hline 500000163734 & CxCL3 & 508.135970 & 13.92110862 & 5.189868584 & $2.86 \mathrm{E}-22$ & up \\
\hline $\begin{array}{l}\text { G000000170345 } \\
0.000000185897\end{array}$ & & $\begin{array}{l}41743.043758 \\
2 \\
20383130\end{array}$ & $\begin{array}{l}1366.7133 \\
0667006456\end{array}$ & $\begin{array}{l}4.93275326 \\
4.918469322\end{array}$ & $\begin{array}{c}7.83 \mathrm{E}-10 \\
0.00029004\end{array}$ & up \\
\hline SG000000162772 & $\begin{array}{l}\text { FiAR3 } \\
\text { CxCL14 }\end{array}$ & $\begin{array}{l}20.038383130 \\
0.324473\end{array}$ & 0.672006456 & $\begin{array}{l}4.9184696382 \\
.12 .72784055\end{array}$ & $\begin{array}{l}0.0000290004 \\
2.33 E-89\end{array}$ & $\begin{array}{l}\text { up } \\
\text { down }\end{array}$ \\
\hline G000000000971 & ADIPOQ & 0.973418 & 3031.047 & $\begin{array}{l}-11.60446959 \\
-12\end{array}$ & $2.16 \mathrm{E}-05$ & $\begin{array}{l}\text { down } \\
\text { down }\end{array}$ \\
\hline G00000107518 & ACKR1 & 0.334318 & 639.6166 & - 10.90177016 & $3.72 \mathrm{E}-48$ & down \\
\hline $\begin{array}{l}\text { S6G0000001627711 } \\
\text { \$G00000124813 }\end{array}$ & $\begin{array}{l}\text { CADM3 } \\
\text { RPL10P9 }\end{array}$ & $\begin{array}{l}0.324473 \\
0.983152\end{array}$ & $\begin{array}{l}292.08622 \\
458.0547\end{array}$ & $\begin{array}{l}-8.914088932932 \\
-8.86389207\end{array}$ & $\begin{array}{l}2.9112-29 \\
3.53 \mathrm{E}-37\end{array}$ & $\begin{array}{l}\text { down } \\
\text { down }\end{array}$ \\
\hline SG00000151575 & L1CAM & & $\begin{array}{l}490.0313 \\
290.034\end{array}$ & 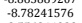 & $\begin{array}{l}3.01 \mathrm{E}-27 \\
438\end{array}$ & $\begin{array}{l}\text { down } \\
\text { down }\end{array}$ \\
\hline ENSG00000125648 & P116 & 0.334207 & 125.8585 & 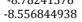 & $\begin{array}{l}4.92 \mathrm{E}-16 \\
16\end{array}$ & $\begin{array}{l}\text { down } \\
\text { down }\end{array}$ \\
\hline $\begin{array}{l}\text { ISGG00000112984 } \\
\text { ISG00000135917 }\end{array}$ & $\begin{array}{l}\text { ITTL1 } \\
\text { HOXA5 }\end{array}$ & $\begin{array}{l}2.320536 \\
8.611952\end{array}$ & $\begin{array}{l}742.3876 \\
2713315\end{array}$ & $\begin{array}{l}-8.3211570001 \\
-8.295900699\end{array}$ & $\begin{array}{l}2.25 \mathrm{E} \cdot 11 \\
14 \mathrm{E} \cdot 23\end{array}$ & $\begin{array}{l}\text { down } \\
\text { down }\end{array}$ \\
\hline ISG00000207744 & RELN & $\begin{array}{l}8.61952 \\
0.658680\end{array}$ & $\begin{array}{l}2713.315 \\
196.037\end{array}$ & $\begin{array}{l}-8.2995006999 \\
-8.217333174\end{array}$ & $\begin{array}{l}1.466-23 \\
1.80 \mathrm{E}-21\end{array}$ & $\begin{array}{l}\text { down } \\
\text { down }\end{array}$ \\
\hline
\end{tabular}

Table 4. Top 10 up-regulated and down- regulated known IncRNAs (TAD vs.NA)

\begin{tabular}{|c|c|c|c|c|c|c|c|}
\hline Gene & chromosomal position & TAD normalize & NA normalize & $\log \mathrm{PC}$ & P.value & Up/Down & $\begin{array}{l}\text { Nearest } \\
\text { Nans }\end{array}$ \\
\hline ENSG000000229807 & $\begin{array}{c}\text { Chromosome X: } \\
\text { 73,820,651: } \\
73,852,753:\end{array}$ & 6330.346 & 27.63586 & 7.839598743 & $8.58 \mathrm{E}-07$ & up & сHIC1 \\
\hline ENSG000000230838 & $\begin{array}{l}\text { Crromososme e } 2 \\
215,718,043 . \\
215,719,424:\end{array}$ & 361.7735 & 7.766359 & 5.541704646 & 1.97E-18 & uр & MREG \\
\hline ENSG00000260823 & $\begin{array}{l}\text { Chromomosome 16: } \\
56,6099,501: \\
56,61,35: \text { : }\end{array}$ & 26.59032 & 1.034146 & 4.684389886 & $3.04 \mathrm{E} .05$ & up & MT2A \\
\hline ENSG00000236882 & $\begin{array}{c}95,852,232: \\
95,860,133:+ \\
9\end{array}$ & 174.2612 & 8.760695 & 4.314062588 & 0.000102164 & up & ELL2 \\
\hline ENSG00000241163 & $\begin{array}{l}\text { Chromosome } \\
72,035,300 \\
72,29,503:=\end{array}$ & 72.20052 & 4.131444 & 4.127291184 & $1.31 \mathrm{E}-07$ & up & RYBP \\
\hline ENSG000000272021 & $\begin{array}{l}\text { 95,894,309: } \\
95,849,855:+\end{array}$ & 47.80642 & 2.923231 & 4.031568536 & $3.12 \mathrm{E}-06$ & up & GLRX \\
\hline ENSG00000269927 & 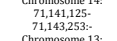 & 40.20674 & 2.846981 & 3.819932785 & $2.33 \mathrm{E}-05$ & up & PCNX1 \\
\hline ENSG000000231817 & $\begin{array}{l}\text { Chromosome 13: } \\
46,455,135: \\
46,486,506:\end{array}$ & 31.94922 & 2.381508 & 3.745833117 & 0.000286799 & up & KIAA0226L \\
\hline ENSG00000260135 & 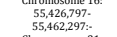 & 35.78173 & 3.67111 & 3.284934794 & 0.000192417 & ир & MMP2 \\
\hline ENSG00000280018 & 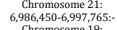 & 30.89401 & 3.545312 & 3.123342413 & 0.000262283 & up & U2AF1L5 \\
\hline ENSG00000267107 & $\begin{array}{c}41,450,169: \\
41,500,649: \\
4\end{array}$ & 7.106935 & 115.2637 & -4.01956677 & $7.33 \mathrm{E}-05$ & down & PCAT19 \\
\hline ENSG00000267603 & 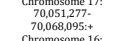 & 0.01 & 13.02435 & -10.34699596 & 0.000231985 & down & KCN116 \\
\hline ENSG00000261685 & $\begin{array}{l}50,654,890: \\
50,649,249 ;:\end{array}$ & 229.7083 & 1645.072 & -2.840276529 & $5.90 \mathrm{E} \cdot 08$ & down & NKD1 \\
\hline ENSG000000179136 & 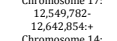 & 136.1124 & 579.9515 & -2.091133945 & 0.000178449 & down & MYOCD \\
\hline ENSG600000259129 & $\begin{array}{l}\text { Chromosome 14: } \\
\text { 47,769,954: } \\
47,795,092:\end{array}$ & 0.30847 & 14.45235 & .5.550029836 & 0.000315329 & down & MDGA2 \\
\hline ENSG00000226197 & $\begin{array}{l}13.446,491 . \\
13,487,51: \\
\text { Chromosome } 2:\end{array}$ & 3.107876 & 61.21916 & -4.299982347 & $8.72 E-06$ & down & MPDZ \\
\hline ENSG000000163364 & $\begin{array}{l}176,629,599 . \\
176,637,931: \\
\end{array}$ & 2.866995 & 30.53217 & -3.412718981 & 0.000127288 & down & MTX2 \\
\hline ENSG00000240405 & 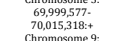 & 28.96542 & 693.4513 & -4.581390953 & $1.76 \mathrm{E} \cdot 14$ & down & MITF \\
\hline ENSG00000234665 & $\begin{array}{l}62,855,999 . \\
62,89087 \% \\
\text { Chromosome 1: }\end{array}$ & 7.150474 & 54.02638 & -2.917553238 & 0.000144046 & down & KGELP1 \\
\hline ENSG00000215808 & $\begin{array}{l}238,480,384 . \\
238,486,023:\end{array}$ & 1.274606 & 64.41237 & -5.659214104 & $2.03 \mathrm{E}-09$ & down & 2P4 \\
\hline
\end{tabular}

Table 6. Information of known aortic dissection biomarker genes in TAD

\begin{tabular}{|c|c|c|c|}
\hline Gene & name & P-value & $\log F C$ \\
\hline up-regulation & & & \\
\hline IL6R & ENSG00000160712 & 0.006168 & 2.715744 \\
\hline $\begin{array}{l}\text { MAP4K4 } \\
\text { down-regulation }\end{array}$ & ENSG00000071054 & 0.001657 & 1.702181 \\
\hline TIMP1 & ENSG00000130758 & 0.007265 & 0.660726 \\
\hline FBLN5 & ENSG00000140092 & 0.039146 & 0.526762 \\
\hline MYH11 & ENSG00000133392 & 0.021778 & 0.33909 \\
\hline TIMP3 & ENSG00000100234 & 0.010745 & 0.249099 \\
\hline ACTA2 & ENSG00000107796 & 0.028532 & 0.222923 \\
\hline ACTN2 & ENSG00000077522 & 0.048531 & 0.211353 \\
\hline P4HA1 & ENSG00000122884 & 0.005896 & 2.324997 \\
\hline ITGB4 & ENSG00000132470 & 0.019307 & 1.703597 \\
\hline
\end{tabular}

mRNAs were mainly associated with the following functions: inflammatory response, immune response, signal transduction, cell-cell signaling, $\mathrm{T}$ cell proliferation involved in immune response, negative regulation of inflammatory response, cellular response to lipopolysaccharide, heterotypic cell-cell adhesion, leukocyte migration, chemotaxis. Downregulated mRNAs were associated with the following functions: angiogenesis, regulation of blood pressure, leukocyte migration, platelet degranulation, uterus development, response to hypoxia, glossopharyngeal nerve morphogenesis, planar cell polarity pathway involved in axis elongation, cell adhesion, and positive regulation of gene expression (Fig. 4A).

A KEGG enrichment analysis indicated that the up-regulated mRNAs were chiefly involved in Rheumatoid arthritis, leishmaniasis, intestinal immune network for IgA production, systemic lupus erythematosus, pertussis, cytokine-cytokine receptor interaction, TNF signaling pathway, hematopoietic cell lineage, staphylococcus aureus infection, osteoclast differentiation. The down-regulated mRNAs were involved in PPAR signaling pathway, proteoglycans in cancer, vascular smooth muscle contraction, bacterial invasion of epithelial cells, cGMP-PKG signaling pathway, fatty acid elongation, signaling pathways regulating, pluripotency of stem cells, propanoate metabolism, adrenergic signaling in cardiomyocytes, 
Fig. 4. GO and KEGG enrichment analyses for all aberrantly expressed mRNAs. (A) GO enrichment analysis for all aberrantly expressed mRNAs in TAD (Top 10). (B) KEGG enrichment analysis for all aberrantly expressed mRNAs in TAD (Top 10).

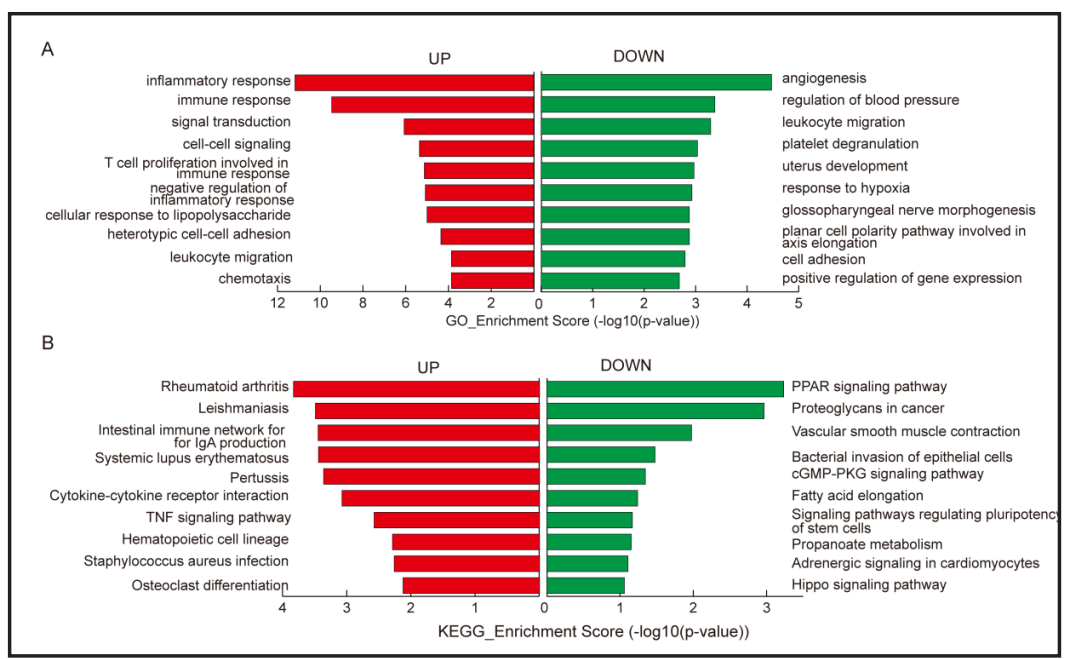

Fig. 5. The aberrantly expressed IncRNAs regulated the target genes in cis and trans. (A) GO enrichment analysis for the aberrantly expressed mRNAs which were predicted to be regulated by the aberrantly expressed lncRNAs in cis. (B) The up-regulated IncRNA (ENSG00000269936) was significantly correlated with the expression of its up-regulated mRNA (mitogen-activated protein kinase kinase 6, MAP2K6). (C) GO enrichment analysis for aberrantly expressed mRNAs which were predicted to be regulated by the aberrantly expressed IncRNAs in trans. (D) Coexpression IncRNA-mRNA network shows the potential relationship between aberrantly expressed mRNAS and lncRNAs in trans. (E) and (F) qRT-PCR analysis shows the relative expression levels of one lncRNA (lnc_1421) and three

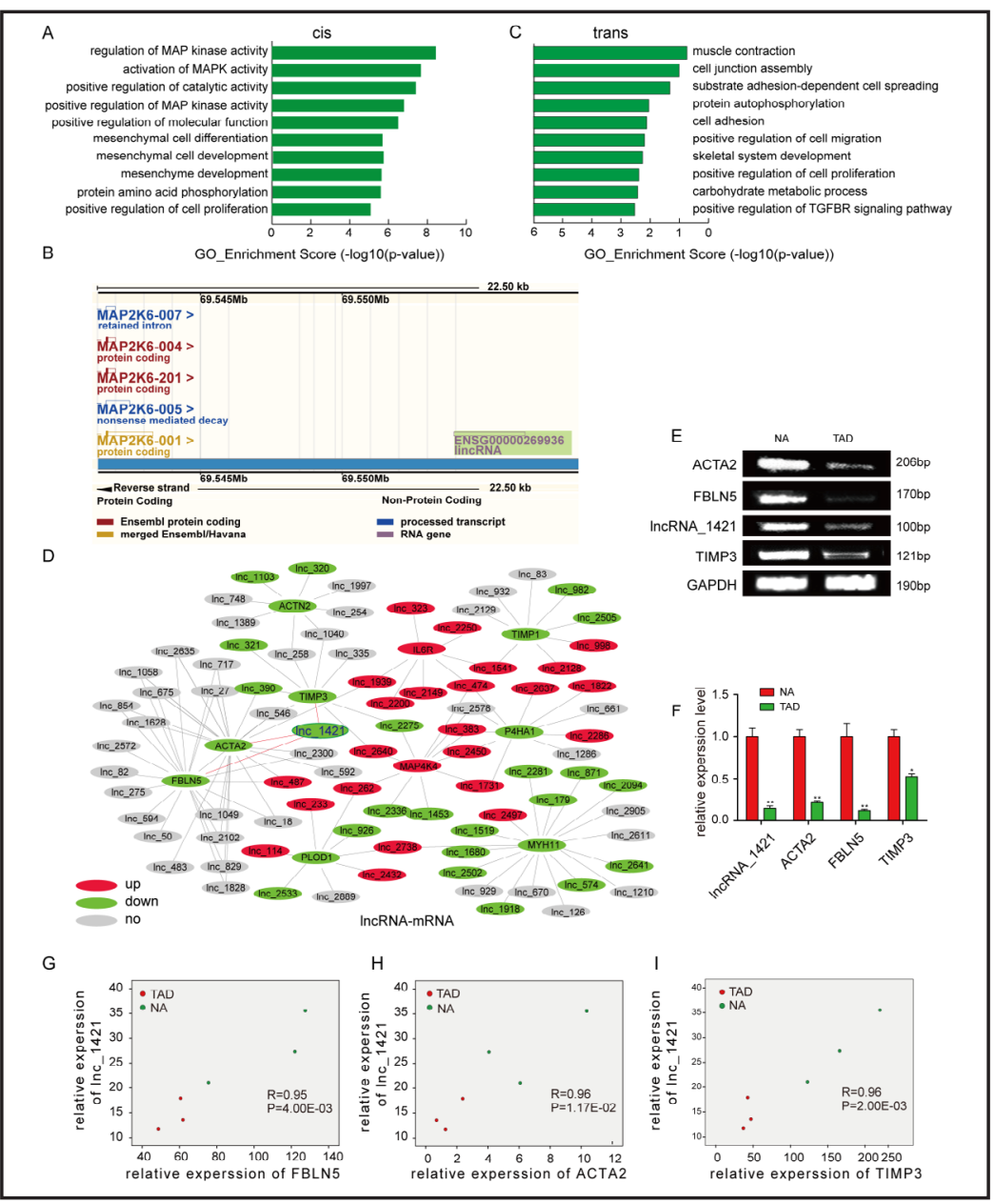
aberrantly expressed mRNAs (FBLN5, ACTA2, and TIMP3) in TAD and NA. GAPDH was amplified as an internal control. (G), (H), and (I) Scatter plots show the correlations between the expression of FBLN5 and lnc_1421, ACTA2, and lnc_1421, as well asTIMP3 and lnc_1421. NA represents normal aortic tissue; TAD represents thoracic aortic dissection tissue. ${ }^{*} \mathrm{P}<0.05$ vs. NA. ${ }^{* *} \mathrm{P}<0.01$ vs. NA. 
Fig. 6. Coexpression l n c R N A miRNA-mRNA network. (A) The regulatory network of lncRNA XIST and 202 potential targeted miRNAs. (B) The chart showed that 29 out of 202 predicted miRNAs were reported significantly aberrantly expressed in TAD. (C) The network of lncRNA XIST and those 29

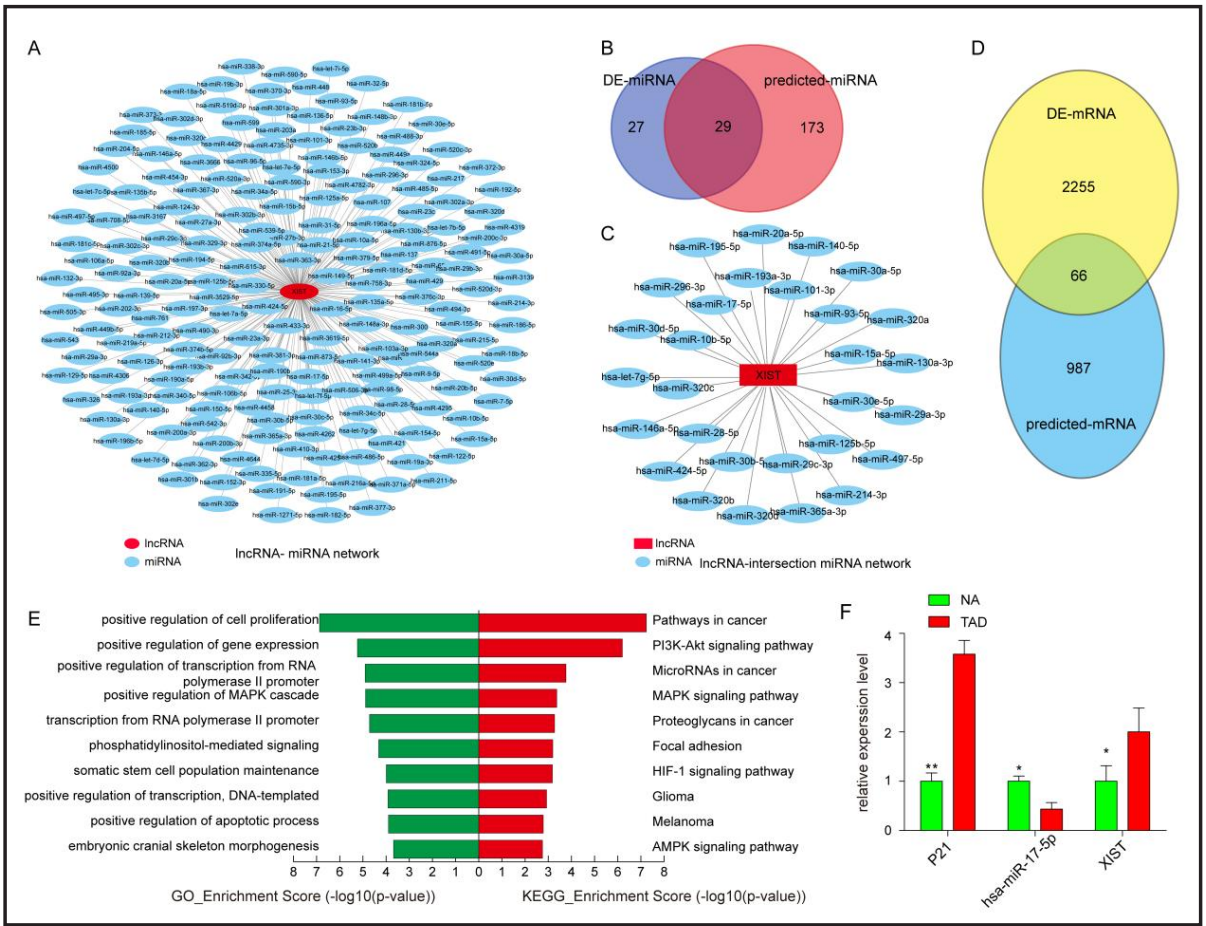
miRNAs. (D)

1053 mRNAs was predicted to be targeted by those 29 miRNAs. Among them, 66 mRNAs were significantly aberrantly expressed in TAD in our data. (E) GO and KEGG enrichment analyses for those 66 aberrantly expressed mRNAs which were predicted to be regulated by co-expression IncRNA xist-miRNA-mRNA network. (F) Histogram of IncRNA XIST, has-miR-17-5p, and p21 relative expression levels in TAD and NA assessed by qRT-PCR. NA represents normal aortic tissue; TAD represents thoracic aortic dissection tissue. ${ }^{* *} \mathrm{P}<0.01$ vs. NA.

and hippo signaling pathway (Fig. 4B). These results suggested that those up-regulated mRNAs may directly promote the TAD pathological process, whereas down-regulated mRNAs probably suppress vascular smooth muscle contraction, which may indirectly participate in the TAD pathological process.

Prediction of functional effects of aberrantly expressed IncRNAs on target mRNAs in cis and trans

A GO enrichment analysis was also applied to examine the regulatory functions of aberrantly expressed IncRNAs on aberrantly expressed mRNAs in cis and trans. The aberrantly expressed mRNAs targeted by aberrantly expressed lncRNAs in cis were involved in multiple biological processes, such as regulation of MAP kinase activity, activation of MAPK activity, positive regulation of catalytic activity, positive regulation of MAP kinase activity, positive regulation of molecular function, mesenchymal cell differentiation, mesenchymal cell development, mesenchymal development, protein amino acid phosphorylation, and positive regulation of cell proliferation (Fig. 5A). For example, the expression level of upregulated lncRNA (ENSG00000269936) was potential correlated with the expression of its adjacent mRNA (mitogen-activated protein kinase kinase 6, MAP2K6) $(R=0.940, P<0.01)$ (Fig. 5B).

Aberrantly expressed mRNAs that were targeted by aberrantly expressed lncRNAs in trans were associated with various biological processes, such as Muscle contraction, cell junction assembly, substrate adhesion-dependent cell spreading, protein autophosphorylation, cell adhesion, positive regulation of cell migration, skeletal system development, positive regulation of cell proliferation, carbohydrate metabolic process, and positive regulation of 
Fig. 7. LncRNA XIST regulated the expression of P21 by binding to has-miR-17-5p in vitro. (A) SMCs were co-transfected with either siRNAs of XIST or scramble form. Two days after transfection, the cells were then collected for qRPCR analysis to evaluate relative expression of p21. (B) LncRNA XIST and its predicted miRNA(has-miR17-5p) target. (C) Luciferase re-

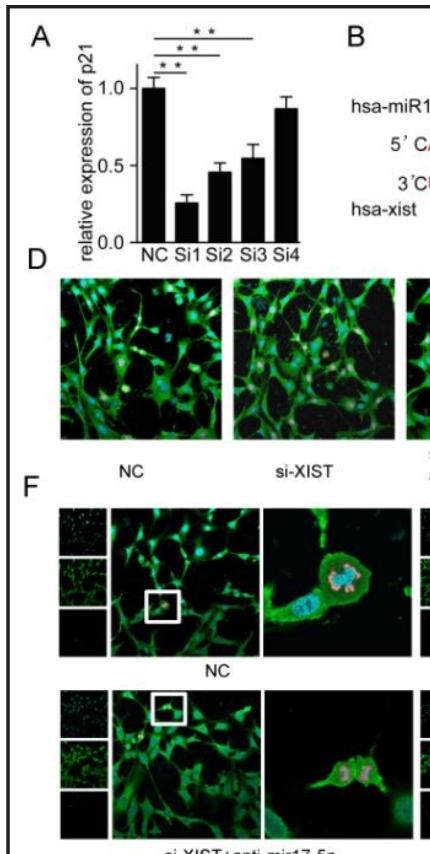

$B$

hsa-miR17-5P

5' CAAAGUGCUUACAGUGCAGgUaG 3' 3'CUUUCACGUUGACUCUUUAACA 5, hsa-xist
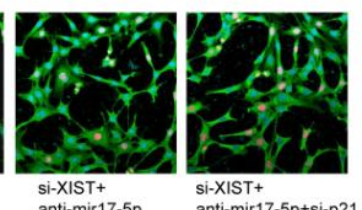
anti-mir17-5p anti-mir17-5p+si-p21
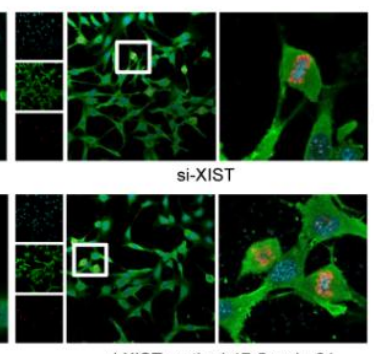

si-XIST+anti-mir17-5p

si-XIST+anti-mir17-5p+si-p21

C

LUC-XIST-WT GCACTT LUC-XIST-MUT ATGTCC
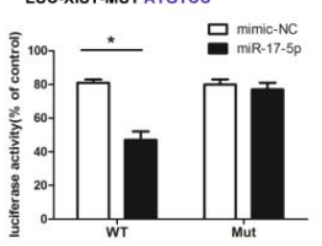

E N. ${ }_{\text {si-XIST }}^{\text {si-XIST+anti-miR 17-5p }}$

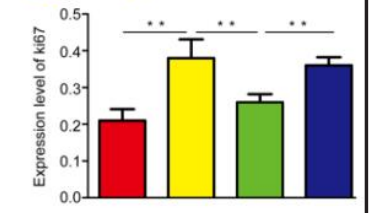

G ${ }^{N C} \square$ si-XIST+anti-miR17-5p $\square$ si-XIST $\square$ si-XIST+anti-miR17-5p+si-p21

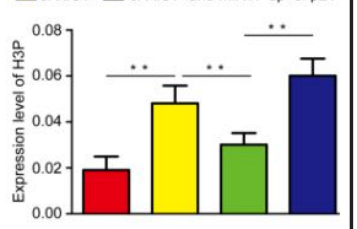
porter analysis of either wild-type or mutant miR-17-5p activity. LncRNA XIST was co-transfected with the wild-type or mutant vector. (D) Representative ki67 fluorescence immuno-cytochemistry images of proliferation of SMCs transfected with si-XIST or si-XIST and anti-miR-17-5p (si-XIST + anti-mir17-5p) or si-XIST, anti-miR-17-5p and si-p21 (si-XIST + anti-mir17-5p + si-p21) or left untreated (NC) for 48h. Blue, nuclei; red, Ki67. (E) Quantification of ki67-stained SMCs. (F) Representative H3P fluorescence immuno-cytochemistry images of proliferation of different genes transfected SMCs. Blue, nuclei; red, H3P. (G) Quantification analysis of proliferating H3P-stained SMCs. The presented values are the mean \pm standard deviation (SD) of three independent preparations. ${ }^{*} \mathrm{P}<0.05,{ }^{* *} \mathrm{P}<0.01$.

TGFBR signaling pathway (Fig. 5C). Moreover, the lncRNA-mRNA network analysis showed the relationships between aberrantly expressed lncRNAs and mRNAs in trans (Fig. 5D). Based on qRT-PCR results, IncRNA_1421 (ENST00000453455.1), FBLN5, ACTA2, and TIMP3 exhibited lower expression in TAD than in NA tissues (Fig. 5E and F). For example, the expression of down-regulated IncRNA_1421 was significantly correlated with the expression of three down-regulated mRNAs (FBLN5, $R=0.950, P<0.01$; ACTA2, $R=0.96, P<0.01$; TIMP3, $R=0.96, P<0.05$ ) (Fig. 5G, $\mathrm{H}$ and I).

\section{LncRNA-miRNA-mRNA network}

LncRNA and mRNA have similar sequences that can be bound by a same miRNA. When bound by miRNA, up-regulated lncRNAs serve as competing endogenous RNAs (ceRNA), that prevents miRNA from binding to natural mRNA targets and increasing the mRNA expression at the post-transcriptional level [20-22]. The IncRNA-miRNA network indicated the relationships between aberrantly expressed lncRNA XIST and its 202 potential target miRNAs (Fig. 6A). 29 out of those miRNAs have been reported significantly aberrantly expressed in TAD (Fig. 6B and C) [8].

Furthermore, those miRNAs was predicted to target 1053 mRNAs. 66 mRNAs were significantly aberrantly expressed in TAD in our data (Fig. 6D). A GO enrichment analysis showed that the aberrantly expressed mRNAs were involved in multiple biological processes, such as positive regulation of cell proliferation, gene expression, transcription from RNA polymerase promoter, MAPK cascade, transcription from RNA polymerase II promoter and apoptotic process, phosphatidylinositol-mediated signaling, somatic stem cell population 
Fig. 8. RUNX1 motif prediction of aberrantly expressed IncRNAs. (A) RUNX1 motif prediction of aberrantly expressed IncRNAs from JASPAR. Upper panel: RUNX1 binding site close to the predicted motifs; lower panel: typical upstream sequences of aberrantly expressed IncRNAs containing the motifs. (B) Genome plots showing the predicted motif location on chr21for RUNX1 binding in each sample. (C) The histogram of three IncRNAs (SRP14-AS1, RP11-348F1.2, and RP11930011.1) relative expression levels in TAD and NA assessed by qRT-PCR. The chromosomal positions of SRP14-AS1, RP11-348F1.2, and RP11-930011.1 were Chromosome 15: 40,039,311$40,067,290$, Chromosome X: 51,396,51151,465,661, and Chromosome 14: $56,310,880-56,345,001$, respectively. NA represents normal aortic tissue; TAD represents thoracic aortic dissection tissue.

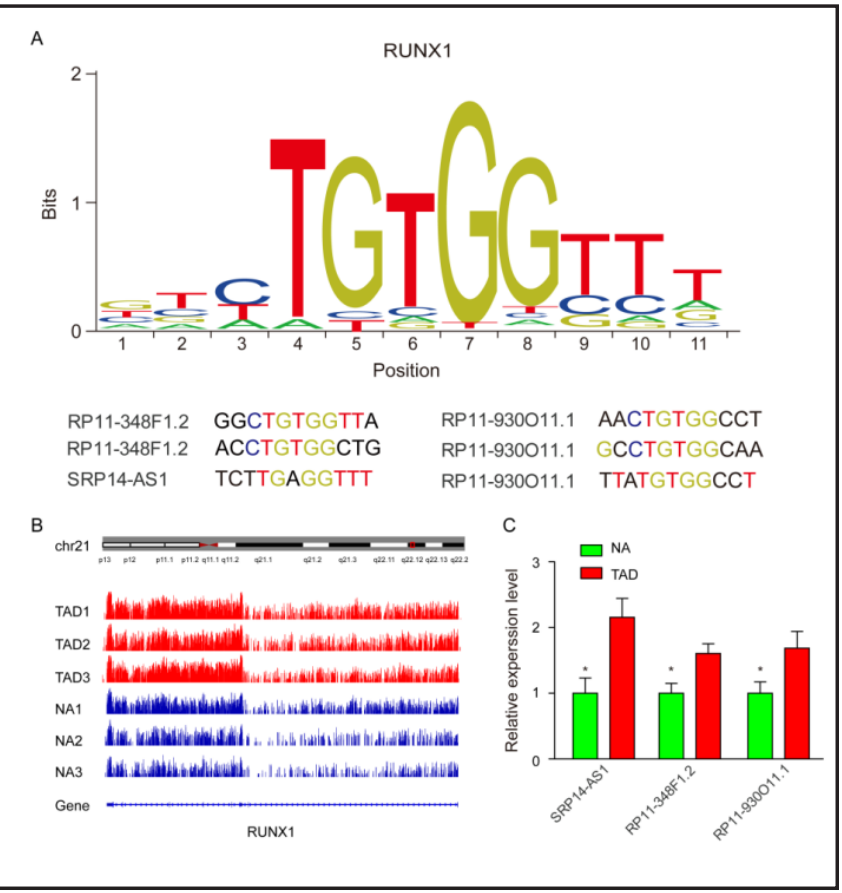
$* \mathrm{P}<0.05$ vs. NA.

maintenance, and embryonic cranial skeleton morphogenesis (Fig. 6E). A KEGG enrichment analysis indicated that the aberrantly expressed mRNAs were involved in the pathways in cancer, PI3K-Akt signaling pathway, MicroRNAs in cancer, MAPK signaling pathway, proteoglycans in cancer, focal adhesion, HIF-1signaling pathway, glioma, melanoma, and AMPK signaling pathway (Fig. 6E).

Additionally, qRT-PCR results showed that P21 and lncRNA XIST exhibited higher expression and that has-miR-17-5p exhibited lower expression in TAD than in normal aortic tissues (Fig. 6F). These qRT-PCR results validated the IncRNA-miRNA-mRNA co-expression relationships.

\section{LncRNA XIST regulated the expression of $P 21$ by binding to has-miR-17-5p in vitro}

To explore whether LncRNA XIST could regulated the expression of P21, an siRNA technology was employed to knockdown lncRNA XIST in SMCs. The results showed that the knockdown of lncRNA XIST significantly reduced the expression of P21 (Fig. 7A).

Through the miRTarBase, IncRNA XIST was predicted to bind to has-miR-17-5p (Fig. 7B). Then luciferase assay system was employed to determine whether LncRNA XIST could directly target the has-miR-17-5p. The luciferase reporter revealed that the level of has-miR17-5p was suppressed by the wild-type lncRNA XIST, whereas it was not influenced by the mutant lncRNA XIST (Fig. 7C).

In addition, Ki67 and H3P immuno-cytochemistry staining and quantitative analysis was performed to investigate proliferation of SMCs transfected with si-XIST or si-XIST and anti-miR-17-5p (si-XIST + anti-mir17-5p) or si-XIST, anti-miR-17-5p and si-p21 (si-XIST + anti-mir17-5p + si-p21) or left untreated for $48 \mathrm{~h}$. The results showed that si-XIST and siXIST + anti-mir17-5p + si-p21 can significantly enhance the relative expression level of Ki-67 and H3P, whereas si-XIST + anti-mir17-5p can not affect relative expression level of either Ki-67 or H3P (Fig. 7D, E, F and G), indicating that IncRNA XIST could regulates $p 21$ by binding to has-miR-17-5p, consequently affected the proliferation of SMCs in vitro.

Prediction of Transcription factors motiffor aberrantly expressed IncRNAs

Transcription factors (TFs) are crucial components that can bind to the promoters of lncRNAs, regulating lncRNA expression, and consequently affecting disease pathogenesis 
[23]. Four aberrantly expressed TFs, Runx1, srebf2, phtf2, and Runx2, were found in the set of aberrantly expressed mRNAs. Runx1, which was up-regulated in our analysis, is reported to be related to TAD $[24,25]$. The predicted binding motifs of three corresponding up-regulated lncRNAs, including ENSG00000248508 (SRP14-AS1), ENSG00000226530 (RP11-348F1.2), and ENSGN00000259719 (RP11-930011.1), were positively correlated with up-regulated $R U N X 1(R=0.982, P<0.001 ; R=0.967, P<0.01 ; R=0.960, P<0.01$, respectively) (Fig. 8A). Genome plots showed the predicted motif location on chr21 for RUNX1binding in each sample (Fig. 8B). Moreover, qRT-PCR results showed that three lncRNAs (SRP14-AS1, RP11-348F1.2, and RP11-930011.1) were expressed at higher levels in TAD than in NA tissues (Fig. 8C). The qRT-PCR results were consistent with the HTS results.

\section{Discussion}

Using HTS technique, we systematically demonstrated not only that both lncRNAs and mRNAs were aberrantly expressed in human TAD tissues compared with those in NA tissues, but also that these lncRNAs may be largely involved in SMC loss and ECM degradation. Importantly, we found that ENSG00000269936, Inc_1421, and the IncRNA XIST could alter the expression levels of MAP2K6, three other genes (FBLN5, ACTA2, and TIMP3), and one mRNA ( $p 21)$ by functioning as cis-regulators, tans-regulators, and ceRNA, respectively. Furthermore, we discovered that three lncRNAs (ENSG00000248508, ENSG00000226530, and EG00000259719) were up-regulated by RUNX1.

By filtering the aberrantly expressed genes located near the aberrantly expressed lncRNAs, we found that several lncRNAs might regulate the transcription of chromosomally adjacent genes in cis. For instant, we found that up-regulated ENSG00000269936 might target protein-coding gene MAP2K6 in cis. MAP2K6 is a member of the MAPK signaling pathway, which is the most highly upregulated pathway in our data. Previous studies have shown that the p38 MAPK signaling pathway is a crucial mechanism in the angiotensin II-mediated up-regulation of MMP-2, pathological mechanical stretch-promoted high expression of MMP-2, and monocyte chemoattractant protein-1-stimulated over-expression of MMP-9 in human aortic smooth muscle cells [26-28]._ENREF_10 Moreover, the p38 MAPK pathway is an important mechanism for increased cyclooxygenase-2 (COX-2) expression in rat aortic fibroblasts treated with angiotensin II [29]. Accordingly, ENSG00000269936 may have regulatory functions in TAD pathogenesis by targeting its adjacent gene, MAP2K6, in cis.

We also discovered that some lncRNAs might regulate the expression of their target genes in trans. For example, down-regulated IncRNA_1421, may target genes in trans, including ACTA2, FBLN5, and TIMP3. LnCRNA_1421 is a 2666-bp IncRNA located on chromosome 9, while ACTA2, FBLN5, and TIMP3, which are associated with TAD, are located on chromosomes 10q2324, 14, and 22, respectively. ACTA2 encodes the aortic smooth muscle actin, and mutations in this gene are associated with the formation of human non-syndromic aortic dissection [30]. In addition, FBLN5 encodes extracellular matrix protein. FBLN5deficient mice show severe vascular remodeling by inhibiting the assembly of mature elastic fibers [31]. Moreover, TIMP3 encodes inhibitors of matrix metalloproteinases, which lead to extracellular matrix degradation [32]. Consequently, lncRNA_1421 might have regulatory functions in TAD by simultaneously regulating the expression of ACTA2, FBLN5, and TIMP3 in trans.

Moreover, lncRNAs could act as ceRNAs by sponging miRNAs and subsequently increase the expression of target mRNAs. Based on the results of the IncRNA-miR-mRNA network and in vitro experiments, we found that up-regulated lncRNA XIST could increase the expression of p21 by acting as a miR-17-5p sponge. Previous studies have demonstrated that miR-17$5 \mathrm{p}$ is involved in the expression of several genes, such as $p 21, P K D 2$, and SOD2, which are associated with aortic diseases [33-35]. Among them, p21 was the only mRNA that was aberrantly expressed in TAD in our study. P21 plays an important role in transcriptional regulation after DNA damage and apoptosis [36, 37]. And MiR-17-5p could also downregulate

\section{KARGER}


the expression of p21 in nasopharyngeal carcinoma cell lines and tissues [38]. It's well known that XIST is not expressed in normal males. However, our data actually indicated the expression of XIST in TAD was significantly higher than that in normal aortic tissues in males. XIST is expressed in male TAD however not in normal male aortic tissues, which maybe part mechanism of TAD. Thus, the IncRNA XIST might have regulatory functions in TAD by acting as a ceRNA via sponging miR-17-5p, thereby increasing the expression of $\mathrm{p} 21$.

Furthermore, we found that several aberrantly expressed lncRNAs might be initially upregulated by TFs binding to DNA motifs of their transcription start site. For example, RUNX1, an aberrantly expressed mRNA, might significantly up-regulate the expression of lncRNAs, such as ENSG00000248508, ENSG00000226530, and EG00000259719. RUNX1 plays an important role in the transcriptional regulation of gene expression and the development of immune system [39]. In human abdominal aortic aneurysms, significantly increased RUNX1 up-regulates MMP-9 expression and contributes to the immune response [24, 25]. Hence, we inferred that, to a certain extent, the aberrantly expressed lncRNAs were up-regulated by RUNX1 and had regulatory functions in TAD by participating in RUNX1-mediated regulation.

In conclusion, the dysregulated IncRNAs in human TAD tissues were capable of regulating the expression of target genes via several potential mechanisms, including serving as cisacting factors, trans-acting factors and ceRNAs, and finally lead to the pathological processes of TAD. These findings indicate that the dysregulated lncRNAs may be a novel therapeutic target to prevent the pathological progression of TAD. However, additional work is needed to verify the functions of these dysregulated lncRNAs in the pathogenesis of TAD. And future studies should be endeavored to make clear whether and how XIST expresses in female TAD, and whether XIST is working in the development of female TAD.

\section{Acknowledgements}

We thank Zhongshan Hospital, Sun Yat-sen University and Guangzhou General Hospital of Guangzhou Military Region for providing aortic specimens. This work was financially supported by grants to Jianping Bin from the National Basic Research Program of China (973 Program) (No.2013CB733804), National Natural Science Foundation of China (No. 81571698, No. 81227801, and No. 81271640), and the Team Program of the Natural Science Foundation of Guangdong Province, China (S2011030003134).

\section{Disclosure Statement}

No conflict of interests exists.

\section{References}

1 Ren Y, Tang Q, Liu W, Tang Y, Zhu R, Li B: Serum Biomarker Identification by Mass Spectrometry in Acute Aortic Dissection. Cell Physiol Biochem 2017;44:2147-2157.

2 Liu W, Wang B, Wang T, Liu X, He X, Liu Y, Li Z, Zeng H: Ursodeoxycholic Acid Attenuates Acute Aortic Dissection Formation in Angiotensin II-Infused Apolipoprotein E-Deficient Mice Associated with Reduced ROS and Increased Nrf2 Levels. Cell Physiol Biochem 2016;38:1391-1405.

3 Song J, Hu B, Qu H, Bi C, Huang X, Zhang M: Mechanical stretch modulates microRNA 21 expression, participating in proliferation and apoptosis in cultured human aortic smooth muscle cells. PLoS One 2012;7:e47657.

4 Liu X, Cheng Y, Zhang S, Lin Y, Yang J, Zhang C: A necessary role of miR-221 and miR-222 in vascular smooth muscle cell proliferation and neointimal hyperplasia. Circ Res 2009;104:476-487.

5 Wu J, Song H-F, Li S-H, Guo J, Tsang K, Tumiati L, Butany J, Yau TM, Ouzounian M, Fu S, David TE, Weisel RD, Li R-K: Progressive Aortic Dilation Is Regulated by miR-17-Associated miRNAs. J Am Coll Cardiol 2016;67:2965-2977. 


\section{Cellular Physiology Cell Physiol Biochem 2018;46:1027-1041 \begin{tabular}{l|l} 
and Biochemistry Published onIIne: April 18, 2018 & $\begin{array}{l}\text { (c) } 2018 \text { The Author(s). Published by S. Karger AG, Basel } \\
\text { www.karger.com/cpb }\end{array}$
\end{tabular}}

6 Zampetaki A, Attia R, Mayr U, Gomes RS, Phinikaridou A, Yin X, Langley SR, Willeit P, Lu R, Fanshawe B, Fava M, Barallobre-Barreiro J, Molenaar C, So PW, Abbas A, Jahangiri M, Waltham M, Botnar R, Smith A, Mayr M: Role of miR-195 in aortic aneurysmal disease. Circ Res 2014;115:857-866.

7 Boon RA, Seeger T, Heydt S, Fischer A, Hergenreider E, Horrevoets AJ, Vinciguerra M, Rosenthal N, Sciacca S, Pilato M, van Heijningen P, Essers J, Brandes RP, Zeiher AM, Dimmeler S: MicroRNA-29 in aortic dilation: implications for aneurysm formation. Circ Res 2011;109:1115-1119.

-8 Liao M, Zou S, Weng J, Hou L, Yang L, Zhao Z, Bao J, Jing Z: A microRNA profile comparison between thoracic aortic dissection and normal thoracic aorta indicates the potential role of microRNAs in contributing to thoracic aortic dissection pathogenesis. J Vasc Surg 2011;53:1341-1349 e1343.

-9 Zhu XF, Shan Z, Ma JY, Wang M, Zhang CX, Liu RM, Wu WB, Shi YW, Li W, Wang SM: Investigating the Role of the Posttranscriptional Gene Regulator MiR-24- 3p in the Proliferation, Migration and Apoptosis of Human Arterial Smooth Muscle Cells in Arteriosclerosis Obliterans. Cell Physiol Biochem 2015;36:1359-1370.

10 Shen S, Jiang H, Bei Y, Xiao J, Li X: Long Non-Coding RNAs in Cardiac Remodeling. Cell Physiol Biochem 2017;41:1830-1837.

11 Li Z, Dou P, Liu T, He S: Application of Long Noncoding RNAs in Osteosarcoma: Biomarkers and Therapeutic Targets. Cell Physiol Biochem 2017;42:1407-1419.

12 Congrains A, Kamide K, Katsuya T, Yasuda O, Oguro R, Yamamoto K, Ohishi M, Rakugi H: CVD-associated non-coding RNA, ANRIL, modulates expression of atherogenic pathways in VSMC. Biochem Biophys Res Commun 2012;419:612-616.

13 Bell RD, Long X, Lin M, Bergmann JH, Nanda V, Cowan SL, Zhou Q, Han Y, Spector DL, Zheng D, Miano JM: Identification and initial functional characterization of a human vascular cell-enriched long noncoding RNA. Arterioscler Thromb Vasc Biol 2014;34:1249-1259.

14 Wang S, Zhang X, Yuan Y, Tan M, Zhang L, Xue X, Yan Y, Han L, Xu Z: BRG1 expression is increased in thoracic aortic aneurysms and regulates proliferation and apoptosis of vascular smooth muscle cells through the long non-coding RNA HIF1A-AS1 in vitro. Eur J Cardiothorac Surg 2015;47:439-446.

15 Wu G, Cai J, Han Y, Chen J, Huang ZP, Chen C, Cai Y, Huang H, Yang Y, Liu Y, Xu Z, He D, Zhang X, Hu X, Pinello L, Zhong D, He F, Yuan GC, Wang DZ, Zeng C: LincRNA-p21 regulates neointima formation, vascular smooth muscle cell proliferation, apoptosis, and atherosclerosis by enhancing p53 activity. Circulation 2014;130:1452-1465.

16 Vigetti D, Deleonibus S, Moretto P, Bowen T, Fischer JW, Grandoch M, Oberhuber A, Love DC, Hanover JA, Cinquetti R, Karousou E, Viola M, D’Angelo ML, Hascall VC, De Luca G, Passi A: Natural Antisense Transcript for Hyaluronan Synthase 2 (HAS2-AS1) Induces Transcription of HAS2 via ProteinO-GlcNAcylation. J Biol Chem 2014;289:28816-28826.

17 Li JH, Liu S, Zhou H, Qu LH, Yang JH: starBase v2.0: decoding miRNA-ceRNA, miRNA-ncRNA and proteinRNA interaction networks from large-scale CLIP-Seq data. Nucleic Acids Res 2014;42:D92-97.

18 St Laurent G, Wahlestedt C, Kapranov P: The Landscape of long noncoding RNA classification. Trends Genet 2015;31:239-251.

19 Lindsay ME, Dietz HC: Lessons on the pathogenesis of aneurysm from heritable conditions. Nature 2011;473:308-316.

-20 Cesana M, Cacchiarelli D, Legnini I, Santini T, Sthandier O, Chinappi M, Tramontano A, Bozzoni I: A long noncoding RNA controls muscle differentiation by functioning as a competing endogenous RNA. Cell 2011;147:358-369.

21 Ge D, Han L, Huang S, Peng N, Wang P, Jiang Z, Zhao J, Su L, Zhang S, Zhang Y, Kung H, Zhao B, Miao J: Identification of a novel MTOR activator and discovery of a competing endogenous RNA regulating autophagy in vascular endothelial cells. Autophagy 2014;10:957-971.

22 Ma MZ, Chu BF, Zhang Y, Weng MZ, Qin YY, Gong W, Quan ZW: Long non-coding RNA CCAT1 promotes gallbladder cancer development via negative modulation of miRNA-218-5p. Cell Death Dis 2015;6:e1583.

-23 Gong C, Li Z, Ramanujan K, Clay I, Zhang Y, Lemire-Brachat S, Glass DJ: A long non-coding RNA, LncMyoD, regulates skeletal muscle differentiation by blocking IMP2-mediated mRNA translation. Dev Cell 2015;34:181-191.

24 Nischan J, Gatalica Z, Curtis M, Lenk GM, Tromp G, Kuivaniemi H: Binding sites for ETS family of transcription factors dominate the promoter regions of differentially expressed genes in abdominal aortic aneurysms. Circ Cardiovasc Genet 2009;2:565-572. 


\section{Cellular Physiology Cell Physiol Biochem 2018;46:1027-1041 \begin{tabular}{l|l} 
and Biochemistry Published online: April 18, 2018 & $\begin{array}{l}\text { (c) } 2018 \text { The Author(s). Published by S. Karger AG, Basel } \\
\text { www.karger.com/cpb }\end{array}$ \\
\hline
\end{tabular}}

25 Pahl MC, Erdman R, Kuivaniemi H, Lillvis JH, Elmore JR, Tromp G: Transcriptional (ChIP-Chip) Analysis of ELF1, ETS2, RUNX1 and STAT5 in Human Abdominal Aortic Aneurysm. Int J Mol Sci 2015;16:11229-11258.

-26 Liu CF, Zhang J, Shen K, Gao PJ, Wang HY, Jin X, Meng C, Fang NY: Adventitial gene transfer of catalase attenuates angiotensin II-induced vascular remodeling. Mol Med Rep 2015;11:2608-2614.

-27 Liu X, Huang X, Chen L, Zhang Y, Li M, Wang L, Ge C, Wang H, Zhang M: Mechanical stretch promotes matrix metalloproteinase-2 and prolyl-4-hydroxylase alpha1 production in human aortic smooth muscle cells via Akt-p38 MAPK-JNK signaling. Int J Biochem Cell Biol 2015;62:15-23.

-28 Yang CQ, Li W, Li SQ, Li J, Li YW, Kong SX, Liu RM, Wang SM, Lv WM: MCP-1 stimulates MMP-9 expression via ERK 1/2 and p38 MAPK signaling pathways in human aortic smooth muscle cells. Cell Physiol Biochem 2014;34:266-276.

-29 Beltrán AE, Briones AM, García-Redondo AB, Rodríguez C, Miguel M, Álvarez Y, Alonso MJ, MartínezGonzález J, Salaices M: p38 MAPK contributes to angiotensin II-induced COX-2 expression in aortic fibroblasts from normotensive and hypertensive rats. Journal of Hypertension 2009;27:142-154.

30 Guo DC, Pannu H, Tran-Fadulu V, Papke CL, Yu RK, Avidan N, Bourgeois S, Estrera AL, Safi HJ, Sparks E, Amor D, Ades L, McConnell V, Willoughby CE, Abuelo D, Willing M, Lewis RA, Kim DH, Scherer S, Tung PP, Ahn C, Buja LM, Raman CS, Shete SS, Milewicz DM: Mutations in smooth muscle alpha-actin (ACTA2) lead to thoracic aortic aneurysms and dissections. Nat Genet 2007;39:1488-1493.

-31 Spencer JA, Hacker SL, Davis EC, Mecham RP, Knutsen RH, Li DY, Gerard RD, Richardson JA, Olson EN, Yanagisawa $\mathrm{H}$ : Altered vascular remodeling in fibulin-5-deficient mice reveals a role of fibulin-5 in smooth muscle cell proliferation and migration. Proc Natl Acad Sci U S A 2005;102:2946-2951.

-32 Zhang X, Shen YH, LeMaire SA: Thoracic aortic dissection: are matrix metalloproteinases involved? Vascular 2009;17:147-157.

-33 Kavurma MM, Khachigian LM: Vascular smooth muscle cell-specific regulation of cyclin-dependent kinase inhibitor p21(WAF1/Cip1) transcription by Sp1 is mediated via distinct cis-acting positive and negative regulatory elements in the proximal p21(WAF1/Cip1) promoter. J Cell Biochem 2004;93:904-916.

-34 Hao F, Wu DD, Xu X, Cui MZ: Histamine induces activation of protein kinase D that mediates tissue factor expression and activity in human aortic smooth muscle cells. Am J Physiol Heart Circ Physiol 2012;303:H1344-1352.

35 Zhou RH, Vendrov AE, Tchivilev I, Niu XL, Molnar KC, Rojas M, Carter JD, Tong H, Stouffer GA, Madamanchi NR, Runge MS: Mitochondrial oxidative stress in aortic stiffening with age: the role of smooth muscle cell function. Arterioscler Thromb Vasc Biol 2012;32:745-755.

-36 Karimian A, Ahmadi Y, Yousefi B: Multiple functions of p21 in cell cycle, apoptosis and transcriptional regulation after DNA damage. DNA Repair (Amst) 2016;42:63-71.

-37 Wu X, Yang N, Zhou WH, Xu J, Chen JJ, Zheng FM, Long ZJ, Yue CF, Ai KX, Liu LL, Wan XY, Liu Q: Up-regulation of P21 inhibits TRAIL-mediated extrinsic apoptosis, contributing resistance to SAHA in acute myeloid leukemia cells. Cell Physiol Biochem 2014;34:506-518.

-38 Chen C, Lu Z, Yang J, Hao W, Qin Y, Wang H, Xie C, Xie R: MiR-17-5p promotes cancer cell proliferation and tumorigenesis in nasopharyngeal carcinoma by targeting p21. Cancer Med 2016;5:3489-3499.

-39 Collins A, Littman DR, Taniuchi I: RUNX proteins in transcription factor networks that regulate T-cell lineage choice. Nat Rev Immunol 2009;9:106-115. 